\title{
Induction of Apoptosis in Human Lung Fibroblasts and Peripheral Lymphocytes in Vitro by Shosaiko-to Derived Phenolic Metabolites
}

\author{
Zhen-Li Liu, ${ }^{1)}$ Sachiko Tanaka, Hiroshi Horigome, Toshihiko Hirano, ${ }^{*}$ and Kitaro Oka \\ Department of Clinical Pharmacology, School of Pharmacy, Tokyo University of Pharmacy and Life Science, 1432-1 \\ Horinouchi, Hachioji, Tokyo 192-0392, Japan. $\quad$ Received August 30, 2001; accepted October 17, 2001
}

\begin{abstract}
Shosaiko-to is a Kampo medicine used for the treatment of chronic hepatitis in Japan. Lately, over 200 cases of interstitial pneumonia have been reported resulting from Shosaiko-to therapy, and the number of cases increased when patients were administrated interferon (IFN)- $\alpha$ at the same time. However, the mechanisms of this Shosaiko-to implicated interstitial pneumonia are not fully understood. In this study, we examined by flow cytometry analysis the in vitro effects of 7 phenolic compounds (lignans and flavonoids), which were detected from human urine after administration of Shosaiko-to, and IFN- $\alpha$ on inducing apoptosis in human lung fibroblasts and peripheral blood mononuclear cells (PBMCs). Among the 7 compounds, baicalein and medicarpin (10 $\mu \mathrm{g} / \mathrm{ml})$ showed significant apoptosis-inducing effects on human PBMCs. In human lung fibroblasts, medicarpin exhibited a significantly higher activity to induce apoptosis compared to the control, and the percentage of cells undergoing apoptosis showed time- and dose-dependent increases. Baicalein $(0.1$ and $1 \mu \mathrm{g} / \mathrm{ml})$, liquiritigenin (10 $\mu \mathrm{g} / \mathrm{ml})$ and davidigenin $(10 \mu \mathrm{g} / \mathrm{ml})$ also showed significant effects after $96 \mathrm{~h}$ treatment. Whereas, baicalin, oroxylin $A$ and wogonin did not show any effect on inducing apoptosis in PBMCs and fibroblasts. Baicalein and medicarpin significantly inhibited the growth and reduced the viability of lung fibroblasts. IFN- $\alpha$ had no apoptosis-inducing effect, and it did not show synergistic interaction with any of the compounds derived from Shosaikoto on inducing apoptosis in both human lung fibroblasts and PBMCs. These results suggested that phenolic compounds found in human post-administrative urine of Shosaiko-to, especially baicalein and medicarpin, exhibited a direct effect on human lung fibroblasts and immune cells to induce apoptosis.
\end{abstract}

Key words shosaiko-to; human lung fibroblast; apoptosis; human peripheral lymphocyte; phenolic compound

Shosaiko-to (TJ-9), a drug-extract preparation comprised of 7 kinds of herbal components, is one of the most commonly used Kampo medicines being mainly indicated for chronic liver injury in Japan. Recently, over 200 cases of interstitial pneumonia have been reported resulting from TJ-9 therapy. ${ }^{2,3)}$ The cases of interstitial pneumonia have been noted to increase when treated with interferon (IFN)- $\alpha$ and TJ-9 at the same time. ${ }^{4)}$ Accordingly, the combination has been contraindicated in Japan since 1994; however, the mechanisms of interstitial pneumonia induced by TJ-9 and IFN- $\alpha$ are not fully understood. It was observed that TJ-9 and IFN- $\alpha$ inhibited the proliferation of lung fibroblasts and increased the production of interleukin-6 (IL-6) by fibroblasts from healthy subjects and patients with idiopathic pulmonary fibrosis (IPF) in vitro. ${ }^{5)}$ Although interstitial pneumonia induced by TJ-9 and/or IFN- $\alpha$ has been suggested to be caused by an allergic-immunological mechanism rather than toxicity, ${ }^{4)}$ other possible explanations remain to be investigated.

Identification of the biologically active compounds might be a solution in clarifying the serious side effect of this crude drug. As possible candidates, 7 phenolic compounds have been found in human urine after administration of TJ-9 (Fig. 1). ${ }^{6}$ They include medicarpin and liquiritigenin derived from Glycyrrhiza glabra; baicalin, baicalein, oroxylin A and wogonin from Scutellaria baicalensis; and davidigenin, a hydrogenated metabolite of liquiritigenin. Since these compounds are actually absorbed into the body and excreted in the urine as free and glucuronide conjugate forms, ${ }^{7)}$ we hypothesized that they would play an important role for the clinical effects of TJ-9. Therefore, in the current study, we investigated the effects of these 7 compounds and IFN- $\alpha$ on inducing apoptosis in human lung fibroblasts and peripheral
Gycyrrhize glabra


Scutelaria burandorsis<smiles>Cc1cc2oc(-c3ccccc3)cc(=O)c2c([Al])c1O</smiles><smiles>CCOc1cc2oc(-c3ccccc3)cc(=O)c2c(O)c1O</smiles>

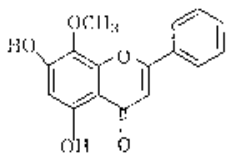

bivilat<smiles>COc1cc2oc(-c3ccccc3)cc(=O)c2c(O)c1O</smiles>

Drokyin :
Metabolite:

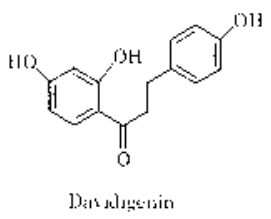

Fig. 1. Chemical Structures of Urinary Products of TJ-9

Baicalin, baicalein, wogonin, oroxylin A, medicarpin and liquiritigenin were found in both constitutional herbal extracts and post-administrative urine of TJ-9. The metabolite, davidigenin was found only in post-administrative urine of TJ-9. 
blood mononuclear cells (PBMCs) in vitro.

\section{MATERIALS AND METHODS}

Chemicals Baicalin, baicalein and wogonin were purchased from Wako Pure Chemical Ind. (Osaka, Japan). Oroxylin A was contributed by Tsumura Co. (Tokyo, Japan). Medicarpin was kindly contributed by Prof. Nomura of Toho University. Liquiritigenin was isolated from Glycyrrhiza glabra. ${ }^{7}$ Davidigenin was synthesized by hydrogenation of isoliquiritigenin. ${ }^{8)}$ All test compounds gave a single peak in HPLC analysis. IFN- $\alpha$ was purchased from Sigma Chemical Co. (St. Louis, MO, U.S.A.). $1 \times$ MEM Eagle (MOD) with Eagle's salts without L-glutamine, $100 \times$ non-essential amino acid for MEM Eagle, and L-glutamine as well as trypsin were obtained from ICN Biomedicals Inc. (Aurora, OH, U.S.A.). Fetal bovine serum (FBS) was produced by JRH Biosciences Co. (Lenexa, KS, U.S.A.). RPMI-1640 medium was purchased from Gibco BRL (Grand Island, NY, U.S.A.). Cell Proliferation Kit I (MTT) was the product of Roche Diagnostics Co. (Indianapolis, IN, U.S.A.).

Peripheral Blood Mononuclear Cell Culture PBMCs were separated from heparinized venous blood collected from healthy volunteers, as described previously. ${ }^{9-11)}$ The cells were suspended in RPMI-1640 medium containing 10\% FBS, $100000 \mathrm{IU} / 1$ penicillin and $100 \mathrm{mg} / 1$ streptomycin at a density of $1 \times 10^{6}$ cells $/ \mathrm{ml}$. Nine hundred eighty microliters of this cell suspension were placed into each well of 24-well flat-bottomed plates (Iwaki Co., Chiba, Japan), and twenty microliters of each test compound solution in ethanol were added at a final concentration of $10 \mu \mathrm{g} / \mathrm{ml}$. Twenty microliters of ethanol were added into the control wells. For analyzing the effect of IFN- $\alpha$ on inducing apoptosis in human PBMCs, $20 \mu \mathrm{l}$ of IFN- $\alpha$ solution in $0.1 \%$ albumin/PBS were added at a final concentration of $10^{3} \mathrm{U} / \mathrm{ml}$ while $20 \mu \mathrm{l}$ of $0.1 \%$ albumin/PBS were added into the control wells.

Fibroblast Culture A human lung diploid fibroblast strain (CCD-11 Lu; American Type Culture Collection) was used between the 5 th and 12 th subcultivations. The cells at a density of $1 \times 10^{5}$ cells $/ \mathrm{ml}$ were incubated in a culture medium consisting $1 \times$ MEM Eagle (MOD) with Eagle's salts without L-glutamine, $10 \% \mathrm{FBS}, 1 \% 100 \times$ non-essential amino acid for MEM Eagle and 1\% L-glutamine. For maintenance of the cell cultures, the fibroblasts were seeded in $75 \mathrm{~cm}^{2}$ flasks and cultured at $37^{\circ} \mathrm{C}$ in a humidified atmosphere of $5 \% \mathrm{CO}_{2} /$ air. The medium was changed every other day and the cells were subcultivated weekly.

Apoptosis Assay To evaluate the percentage of PBMCs and fibroblasts undergoing apoptosis, we performed flow cytometry analysis to detect phosphatidylserine-exposing cells as we described previously. ${ }^{12)}$ One milliliter of PBMCs suspension at a density of $1 \times 10^{6}$ cells $/ \mathrm{ml}$ in a binding buffer $(10$ $\mathrm{mm}$ Hepes/ $\mathrm{NaOH}, \mathrm{pH} 7.4$, containing $140 \mathrm{~mm} \mathrm{NaCl}$ and 2.5 mM $\mathrm{CaCl}_{2}$ ) was incubated with $5 \mu \mathrm{l}$ of Annexin V-FITC (PharMingen Co., San Diego, CA, U.S.A.) and $10 \mu \mathrm{l}$ of 50 $\mu \mathrm{g} / \mathrm{ml}$ propidium iodide (PI) (Sigma) at room temperature for $15 \mathrm{~min}$. A total of 20000 non-gated cells were analyzed using a FACSCalibur analyzer (Becton Dickinson \& Co., Rutherford, NJ, U.S.A.) to obtain dot plot data. These data were further calculated using CellQuest software (Becton Dickinson \& Co.) to provide the percentage of cells undergo- ing apoptosis that were Annexin V-FITC positive and PI negative.

Lung fibroblasts from a confluent monolayer culture were trypsinized and resuspended in medium at a density of $2 \times 10^{5}$ cells $/ \mathrm{ml}$. Nine hundred eighty microliters of this cell suspension were seeded in 24-well flat-bottomed plates (Iwaki Co.). In the cases of analyzing the effects of compounds on inducing apoptosis, $20 \mu \mathrm{l}$ of each test compound solution in ethanol were added to give final concentrations of $0.1,1.0$ and $10 \mu \mathrm{g} / \mathrm{ml}$, respectively. In the cases of analyzing the effects of IFN- $\alpha$ on inducing apoptosis, $20 \mu$ l of IFN- $\alpha$ solution in $0.1 \%$ albumin/PBS were added to give final concentrations of $10-10^{4} \mathrm{U} / \mathrm{ml}$, respectively. After being incubated at $37^{\circ} \mathrm{C}$ in $5 \% \mathrm{CO}_{2}$ /air, the cells were trypsinized, washed twice in ice-cold PBS, and then resuspended in the binding buffer (described above). The percentage of fibroblasts undergoing apoptosis was measured by the same examining manner as we carried out to calculate the percentage of apoptotic PBMCs.

Fibroblast Proliferation Assay Lung fibroblasts between the 5th and 8th subcultivations were used for examining the effects of the compounds on cell growth. Cells from a confluent monolayer culture were trypsinized and resuspended in medium at a density of $2 \times 10^{5}$ cells $/ \mathrm{ml}$. Two hundred microliters of this cell suspension were seeded in 96well flat-bottomed plates (Iwaki Co.) and the cells were incubated for $24 \mathrm{~h}$. Then, the medium was removed and replaced with $196 \mu \mathrm{l}$ of medium containing $0.1 \%$ FBS, and $4 \mu \mathrm{l}$ of ethanol solution containing each test compound were added to give a final concentration of $10 \mu \mathrm{g} / \mathrm{ml}$. Four microliters of ethanol were added into the control wells. The cells were incubated for $72 \mathrm{~h}$ at $37^{\circ} \mathrm{C}$ in $5 \% \mathrm{CO}_{2}$ /air. After the incubation period, the medium in each well was removed and the fibroblasts in the wells were treated with $10 \mu \mathrm{l}$ of $0.25 \%$ trypsin at $37^{\circ} \mathrm{C}$ for $10-15 \mathrm{~min}$, and then $100 \mu \mathrm{l}$ of fresh medium and $10 \mu \mathrm{l}$ of the MTT reagent (Roche Diagnostics Co.) were added. The cells were incubated for another $5 \mathrm{~h}$. Subsequently, $100 \mu \mathrm{l}$ of the solubilization solution (Roche Diagnostics Co.) were added into each well. The plate was allowed to stand overnight in the incubator. After checking for complete solubilization of the purple formazen crystals, the spectrophotometrical absorbance of the samples was measured using a microplate reader. The wavelength to measure absorbance of the formazan product was $570 \mathrm{~nm}$, and the reference wavelength was $630 \mathrm{~nm}$.

Fibroblast viability was detected by staining the cells with PI followed by a flow cytometry assay to obtain a histogram plot data. The percentage of viable cells was calculated using CellQuest software (Becton Dickinson \& Co.).

Statistical Analysis All values obtained were expressed as mean \pm standard deviation (S.D.). Statistics were carried out with Bonferroni/Dun multiple comparison. Calculated $p$ values of less than 0.05 were considered to be significant. Statistical comparisons were supported by $95 \%$ confidence intervals for differences.

\section{RESULTS}

Apoptosis Induction in PBMCs The percentages of cells undergoing apoptosis in PBMCs cultured in the presence of baicalein and medicarpin were $28.31 \pm 3.51$ and 


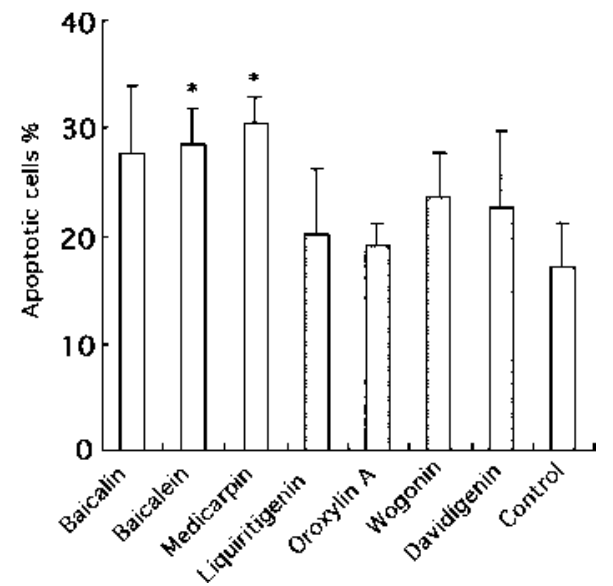

Fig. 2. Induction of Apoptosis by TJ-9-Related Compounds in Human PBMCs

Cells were incubated with $10 \mu \mathrm{g} / \mathrm{ml}$ of compounds derived from TJ-9 for $48 \mathrm{~h}$, and the percentage of cells undergoing apoptosis was detected by flow cytometry analysis. Bars represent mean \pm S.D. of triplicate wells. Statistical significance was based on the control group $(* p<0.05)$.

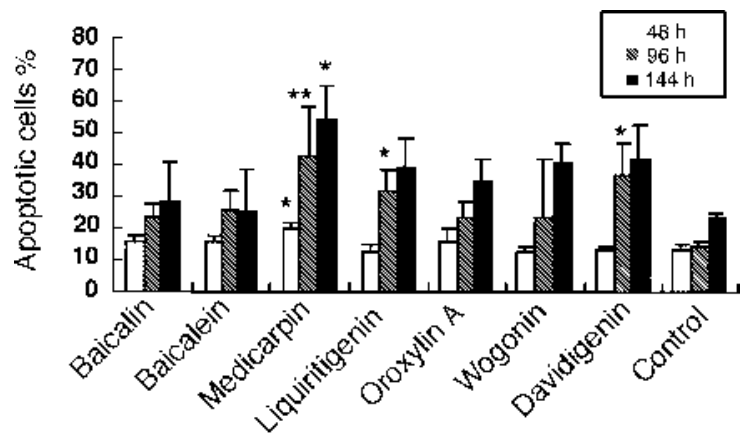

Fig. 3. Induction of Apoptosis by TJ-9-Related Compounds in Human Lung Fibroblasts

Cells were incubated in the presence of $10 \mu \mathrm{g} / \mathrm{ml}$ of the compounds derived from TJ9 for 48,96 or $144 \mathrm{~h}$. The percentage of cells undergoing apoptosis was detected by flow cytometry analysis. Bars represent mean \pm S.D. of triplicate wells. Statistical significance was based on the control group $(* * p<0.01, * p<0.05)$.

$30.49 \pm 2.46$, respectively, which were significantly higher than the control value of $17.08 \pm 4.12 \%(p<0.05)$ (Fig. 2). The other compounds did not show significant activity. The percentage of cells undergoing necrosis, or at the end stage of apoptosis, or already dead (Annexin V-FITC and PI positive) was about $30 \%$ in the controls after a $48 \mathrm{~h}$ incubation period, which was the same as the cells treated with the phenolic compounds (data not shown).

IFN- $\alpha$ had no effect on apoptosis induction in human PBMCs at a concentration of $10^{3} \mathrm{U} / \mathrm{ml}$ for a $48 \mathrm{~h}$ treatment. Moreover, IFN- $\alpha$ and medicarpin showed no synergistic interaction on inducing apoptosis in human PBMCs.

Induction of Apoptosis in Human Lung Fibroblasts The effects of the 7 phenolic compounds at the concentrations of $0.1,1.0$ and $10 \mu \mathrm{g} / \mathrm{ml}$ on inducing apoptosis in human lung fibroblasts were examined. At the concentration of $0.1 \mu \mathrm{g} / \mathrm{ml}$, only baicalein demonstrated a significant effect on the apoptosis induction. Medicarpin revealed significant ability to induce apoptosis at $1 \mu \mathrm{g} / \mathrm{ml}$ for $96 \mathrm{~h}$ and $144 \mathrm{~h}$ treatment $(p<0.05) .10 \mu \mathrm{g} / \mathrm{ml}$ medicarpin for 48,96 , and 144 $\mathrm{h}$ treatment also produced significant results (Fig. 3, $p<0.01$, $p<0.05)$. Baicalein $(1 \mu \mathrm{g} / \mathrm{ml})$, liquiritigenin $(10 \mu \mathrm{g} / \mathrm{ml})$ and davidigenin $(10 \mu \mathrm{g} / \mathrm{ml})$ (Fig. 3) were also observed signifi-

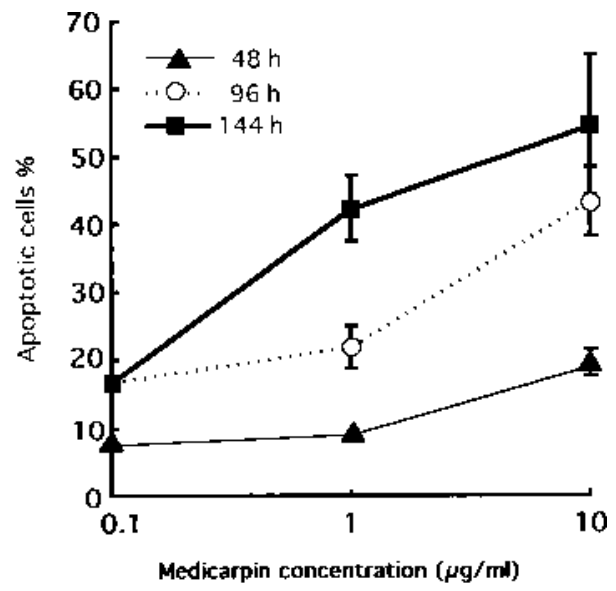

Fig. 4. Time- and Dose-Dependent Induction of Fibroblast-Apoptosis by Medicarpin

Lung fibroblasts were cultured in the presence of medicarpin at concentrations of $0.1,1.0$ and $10 \mu \mathrm{g} / \mathrm{ml}$ for 48,96 and $144 \mathrm{~h}$, respectively. Bars represent mean \pm S.D. of triplicate wells.

cant activity after $96 \mathrm{~h}$ treatment $(p<0.05)$. Whereas, baicalin, oroxylin A and wogonin did not show a significant apoptosis inducing effect in fibroblasts under our experimental conditions. None of the 7 compounds at a concentration of $10 \mu \mathrm{g} / \mathrm{ml}$ for a $24 \mathrm{~h}$ treatment, nor the compounds at a concentration of $1 \mu \mathrm{g} / \mathrm{ml}$ for a $48 \mathrm{~h}$ treatment increased the percentage of cells undergoing apoptosis (data not shown). The percentage of cells undergoing apoptosis induced by medicarpin showed time- and dose-dependent increases (Fig. 4).

The effects of IFN- $\alpha$ on inducing apoptosis in lung fibroblasts were examined in a similar way. Cells were incubated with IFN- $\alpha$ at concentrations $10-10^{4} \mathrm{U} / \mathrm{ml}$ for $144 \mathrm{~h}$ and then stained with Annexin V-FITC and PI. The percentage of cells undergoing apoptosis was detected by flow cytometry analysis. IFN- $\alpha$ had no significant effect on inducing apoptosis in lung fibroblasts under our experimental conditions.

In order to confirm whether the 7 compounds and IFN- $\alpha$ show synergistic interaction on inducing human lung fibroblasts apoptosis, the cells were incubated with each of the 7 compounds at a concentration of $10 \mu \mathrm{g} / \mathrm{ml}$ in the presence of $10^{3} \mathrm{U} / \mathrm{ml}$ IFN- $\alpha$. The results showed that no significant synergistic effect was observed by combination of these agents (data not shown).

Cytostatic Effects on Human Fibroblasts The effects of compounds from TJ-9 on the growth of fibroblasts were examined after a $72 \mathrm{~h}$ incubation period using MTT assay procedures (Fig. 5). The growth of cells treated with medicarpin and baicalein were $72.9 \%$ and $88.6 \%$ of the control, respectively, which were statistically significant $(p<0.01$ and $p<0.05$, respectively).

The effects of medicarpin and baicalein on the viability of fibroblasts were also examined by staining the cells with PI and detected by flow cytometry analysis. Medicarpin and baicalein at $10 \mu \mathrm{g} / \mathrm{ml}$ significantly decreased the percentage of viable cells $(p<0.01, p<0.05$, respectively, data not shown).

Effects of Compounds on Cytokine Production The concentrations of IL- $1 \beta$, TNF- $\alpha$ and IL- 6 in the cultured supernatants of PBMCs and fibroblasts were detected by use of 


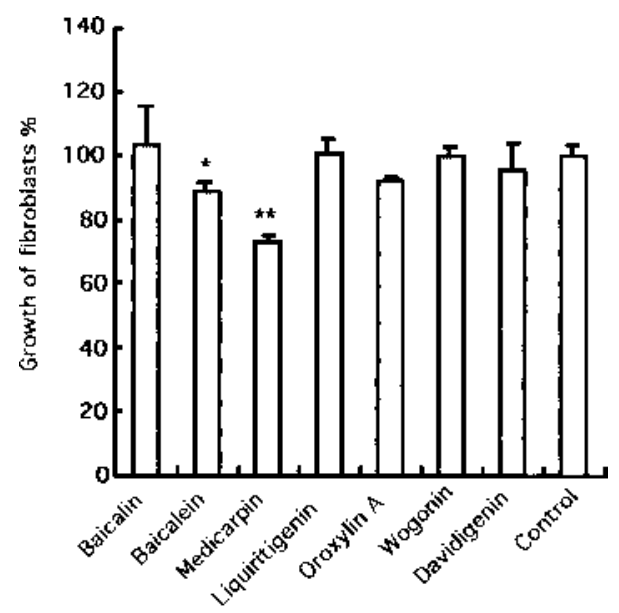

Fig. 5. Effects of TJ-9-Derived Compounds on the Growth of Fibroblasts

Cells were incubated in the presence of each compound at a concentration of 10 $\mu \mathrm{g} / \mathrm{ml}$ for $96 \mathrm{~h}$. The growth of cells was determined by MTT assay. Bars represent mean \pm S.D. of six wells. Statistical significance was based on the control group $(* * p<0.01, * p<0.05)$

ELISA kits. In the current experiments, the 7 compounds from TJ-9 did not induce human PBMCs and lung fibroblasts to secrete detectable amounts of IL- $1 \beta$ and TNF- $\alpha$. IL- 6 concentration was below the detection limit in the PBMC cultures and was not different from that of the controls in fibroblast cultures (data not shown).

\section{DISCUSSION}

Apoptosis is a form of programmed cell death that is characterized by a variety of morphological features, including changes in the plasma membrane such as loss of membrane asymmetry and attachment, cell shrinkage, chromatin condensation and chromosomal DNA fragmentation. Data from this investigation indicated that several compounds, especially medicarpin and baicalein, derived from human postadministrative urine of $\mathrm{TJ}-9^{6}$ ) induced apoptosis in normal human lung fibroblasts and human PBMCs in vitro.

Fibroblasts play an important role in maintaining lung structure and function, and are also the primary cells responsible for the production of connective tissue elements. ${ }^{13)}$ In addition, it is recognized that alveolar fibroblasts may also be important in lung immunity, in regulating ventilation, perfusion relationship and thus gas exchange, and in providing the lung protection from proteolytic and oxidant injury. ${ }^{14)}$ Therefore, it is apparent that the number of fibroblasts within the intestitium is necessary for maintaining the alveolar structure.

Also, in progressive lung fibrosis, fibroblasts play crucial roles as not only target cells but also as pathogenesis-modifying cells. From in vitro and in vivo experiments of lung injury, Adamson et al. ${ }^{15)}$ suggested a reciprocal epithelial-fibroblast control system in the lung. The initiation of lung injury starts with the damage of endothelial and/or epithelial cells. ${ }^{16)}$ Damage to the pulmonary alveolar epithelium is repaired by type II alveolar epithelial cells, which proliferate and differentiate to replace both type I and type II pneumocytes. ${ }^{17)}$ The fibroblast is thought to be a positive modulator of this process through the synthesis of growth factors. ${ }^{18)}$ Thus, we hypothesized that the compounds derived from TJ-
9 induced apoptosis in human lung fibroblasts (Fig. 3) may partly affect the epithelial type II cell proliferation and differentiation.

The compounds from TJ-9 that induced apoptosis in human PBMCs may affect the immune system (Fig. 2). Human PBMCs release factors can modulate fibroblast functions to produce collagen, collagenase, and chemokines. ${ }^{19)}$ In the current study, the 7 compounds from TJ-9 did not induce human PBMCs and lung fibroblasts to secrete detectable amounts of IL- $1 \beta$ and TNF- $\alpha$. The IL- 6 level was below the detection limit in PBMC cultures, and was not significantly different from that of the control cultures in human lung fibroblasts under our experimental conditions. It should be mentioned that patients with hepatitis $\mathrm{C}$ on whom TJ-9 has been frequently used have multiple immunologic abnormalities including high level of serum IL-6. ${ }^{20)}$ Tomioka et al. ${ }^{21}$ ) reported an autopsy case of interstitial pneumonia that was probably induced by TJ-9 administration. They speculated that the progression of interstitial pneumonia in this case might have been caused by chronic hepatitis $\mathrm{C}$ virus in combination with TJ-9-induced lung injury. In the current experiments, however, the PBMCs were from healthy volunteers, and further experiments should be addressed to examine cytokine production by these compounds from PBMCs of patients with hepatitis $\mathrm{C}$.

Although apoptosis has been implicated as one of the homeostatic mechanisms in the lung injury processes, it may play a role in two different ways. In one way, malfunction of the apoptosis mechanism may result in the onset of interstitial pneumonia. Repair after an acute lung injury requires the elimination of proliferating mesenchymal and inflammatory cells from the alveolar airspace or alveolar walls, ${ }^{22)}$ and failure to clear these unwanted cells by apoptosis will prolong the inflammation because of the release of toxic contents from these cells. In the other way, excessive apoptosis may cause extensive cell loss and lead to a failure to clear the apoptotic cell debris which results in the amplification of inflammation by the released cell contents. ${ }^{23)}$ For example, it has been reported that an injection of monoclonal anti-Fas antibody (Jo2) into adult mice caused fulminant hepatitis that was followed by hepatic failure and death. ${ }^{24)}$ Furthermore, it is believed that the development of pneumonitis is caused by the disruption of the balance between various cell populations of the pulmonary parenchyma. ${ }^{16)}$ Therefore, compounds from TJ-9 induced apoptosis in some kinds of cells in the pulmonary parenchyma may disrupt the balance and cause pneumonitis.

The MTT proliferation experiment showed that medicarpin and baicalein inhibited the proliferation of human lung fibroblasts (Fig. 5). This result is consistent with the previous observation indicating that TJ-9 inhibited the proliferation of fibroblasts from healthy subjects and patients with idiopathic pulmonary fibrosis in vitro. ${ }^{5}$ Medicarpin and baicalein also highly decreased fibroblast viability. Baicalein and medicarpin inhibited the proliferation of lung fibroblasts, which may be partly due to their significant effects on inducing fibroblast apoptosis. The effect of IFN- $\alpha$ on the proliferation of fibroblasts is uncertain. Carre et $a l^{25)}$ observed that IFN- $\alpha$ inhibited the proliferation of fibroblasts; however, the another study showed that IFN- $\alpha$ had no growth modulating effect on fibroblasts. ${ }^{26)}$ The current study did not reveal that 
IFN- $\alpha$ itself induced apoptosis in lung fibroblasts and PBMCs, and it did not demonstrate synergistic interaction with any of the compounds derived from TJ-9 on inducing apoptosis in human PBMCs as well as lung fibroblasts.

Cells at different stages of apoptosis might co-exist, and the overall rate of cellular destruction might be very rapid. Therefore, it is quite possible that only a minimal percentage of cells undergoing apoptosis could be detected at any one time during the culture period. Additionally, the time lag for apoptosis induction also changed upon various stimuli even in the same cell line. For example, apparent changes in apoptosis of HL-60 cells were observed after $24 \mathrm{~h}$ in culture with tangeretin, whereas actinomycin D caused apoptosis in these cells within $6 \mathrm{~h}$ in culture. ${ }^{27)}$ Thus, in the current experiment, the cells were incubated with each of the 7 compounds from TJ-9 at varying doses and intervals before analyzing their effects on inducing apoptosis. The data of our present study showed that phenolic compounds, especially medicarpin and baicalein, detected in human urine after administration of TJ9 induced apoptosis in human lung fibroblasts and PBMCs. These observations raise the possibility that phenolic compounds actually absorbed into the human body may be partly resposible for interstitial pneumonia resulting from TJ-9 therapy.

\section{REFERENCES AND NOTES}

1) Present address: Institute of Basic Theory, China Academy of Traditional Chinese Medicine, P. R. China, 100700.

2) Daibo A., Yoshida Y., Kitazawa S., Kosaka Y., Bando T., Sudo M., Nihon Kyobu Shikkan Gakkai Zasshi, 30, 1583-1588 (1992).

3) Kawasaki A., Mizushima Y., Kunitani H., Kitagawa M., Kobayashi M., Am. J. Chin. Med., 22, 329-336 (1994).

4) Ishizaki T., Sasaki F., Ameshima S., Shiozaki K., Takahashi H., Abe Y., Ito S., Kuriyama M., Nakai T., Kitagawa M., Eur. Respir. J., 9, 2691-2696 (1996).

5) Suganuma H., Sato A., Tamura R., Chida K., Curr. Ther. Res., 55, 1551-1561 (1994).

6) Li C., Homma M., Oka K., J. Chromatogr. Biomed. Sci. Appl., 693,
191-198 (1997).

7) Homma M., Oka K., Yamada T., Niitsuma T., Ihto H., Takahashi N., Anal. Biochem., 202, 179-187 (1992).

8) Homma M., Oka K., Taniguchi C., Niitsuma T., Hayashi T., Biomed. Chromatogr., 11, 125-131 (1997).

9) Hirano T., Oka K., Kawashima E., Akiba M., Life Sci., 45, 14071411 (1989).

10) Hirano T., Oka K., Umezawa Y., Hirata M., Oh-i T., Koga M., Clin. Pharmacol. Ther., 63, 465-470 (1998).

11) Hirano T., Akashi T., Keira T., Oka K., Ihoya N., Yoshida M., Clin. Pharmacol. Ther., 68, 532-540 (2000).

12) Horigome H., Homma M., Hirano T., Oka K., Niitsuma T., Hayashi T., Planta Medica, 67, 33-37 (2001).

13) Crystal R. G., Bitterman P. B., Rennard S. I., Hance A. J., Keogh B. A., N. Engl. J. Med., 310, 154-166 (1984).

14) Kapanci Y., Assimacopoulos A., Irle C., Zwahlen A., Gabbiani G., J. Cell Biol., 60, 375-392 (1974).

15) Adamson I. Y., Hedgecock C., Bowden D. H., Am. J. Pathol., 137, 385-392 (1990).

16) Kasper M., Haroske G., Histol. Histopathol., 11, 463 - 483 (1996).

17) Mason R. J., Williams M. C., Type II alveolar epithelial cell. "The Lung: Scientific Foundations," ed. by Crystal R. G., West J. B., New York, Raven, 1991, pp. 235-246.

18) Ulich T. R., Yi E. S., Longmuir K., Yin S., Biltz R., Morris C. F., Housley R. M., Pierce G. F., J. Clin. Invest., 93, 1298-1306 (1994).

19) Yamamoto T., Katayama I., Nishioka K., J. Rheumatol., 26, 609-625 (1999).

20) Fan X. G., Liu W. E., Li C. Z., Wang Z. C., Luo L. X., Tan D. M., Hu G. L., Zhang Z., Mediators Inflamm., 7, 295-297 (1998).

21) Tomioka H., Hashimoto K., Ohnishi H., Fujiyama R., Sakurai T., Tada K., Sakamoto H., Iwasaki H., Nihon Kokyuki Gakkai Zasshi, 37, 1013-1018 (1999)

22) Cox G., Crossley J., Xing Z., Am. J. Respir. Cell Mol. Biol., 12, 232237 (1995).

23) Hagimoto N., Kuwano K., Nomoto Y., Kunitake R., Hara N., Am. J. Respir. Cell Mol. Biol., 16, 91-101 (1997).

24) Ogasawara J., Watanabe-Fukunaga R., Adachi M., Matsuzawa A., Kasugai T., Kitamura Y., Itoh N., Suda T., Nagata S., Nature (London), 364, 806-809 (1993).

25) Carre P., Leophonte P., Rev. Mol. Respir., 10, 193-207 (1993).

26) Thornton S. C., Por S. B., Walsh B. J., Penny R., Breit S. N., J. Leukoc. Biol., 47, 312-320 (1990).

27) Hirano T., Abe K., Gotoh M., Oka K., Br. J. Cancer, 72, 1380-1388 (1995). 